\title{
A New Type of Luminescence in Fishes.
}

\author{
By
}

\author{
C. F. Hickling, B.A.
}

With Plates I-IV and 7 Figures in the Text.

Harvey, in his book, Animal Light (1919), divides luminous organisms into two sub-classes: $(a)$ where the oxidisable material is burned within the cell where it is formed, to produce the light, and $(b)$ where the material is secreted to the exterior and burned outside the cell. He gives a list of animals with extracellular luminescence, and mentions some of the medusæ, hydroids, pennatulids, Pholas and Phyllirhoë, some Cephalopods, decapod and Schizopod crustaceans, all myriapods, and the Balanoglossids. "The remaining organisms burn their material within the cell," a statement which includes the considerable number of fishes known to be luminous. The present paper attempts to describe a luminous organ of a new type found in a Macrurid fish, which falls into the second category of Harvey's classification in that the luminous material is secreted to the outside and not burnt within the cell. The organ seems to be unique in both structure and function.

Malacocephalus laevis (Lowe) is one of the fish which occurs along the outer edge of the continental shelf from Ireland south to Morocco. It is taken in considerable numbers in the trawls of the deep-sea hake trawlers, in depths of over 150 fathoms, though small specimens straggle over into water of 120 fathoms (off Galway, off the Fastnet).

Material was fixed, and experiments were made, during voyages to the deep water on the steam trawlers Tenedos and Trawler Prince in January, March, and May, and I here wish to express my thanks to Chief Skipper J. Yolland, D.s.C., R.N.R., and to Capt. Jones, and to the crews of these ships, for their hospitality, help, and interest in the work.

\section{THE Fish.}

Farran (1924) mentions $M$. laevis as being "very abundant on the hake grounds to the south-west of Ireland," and he notices " a triangular, scale-less, black-coloured depression" between the base of the pelvic fins. He is apparently unaware of any luminous property. in the fish, 
and none of the authorities he quotes seems to have suspected it. Moreover, it is interesting to note that Gilbert and Hubbs (1916), whose classification of the group of Macrurids has been used for identifying the fish, remark a blackish colour on the belly of $M$. nipponensis, and it seems likely that this species also might be found to possess a luminous organ of the type to be described.

Text Fig. 1 represents a ventral view of the fish, which possesses the typical Macrurid figure, comprising a short and thick body, followed by a very long whip-like tail. The pectoral fin of one side is shown at PC, PL are the pelvic fins, and SD 1 and 2 are the black scale-less depressions lying between and behind the bases of these fins. OP is the operculum, and AP is the papilla in which the rectum terminates at the anus. Whether this papilla is the result of the forcing out of the rectum

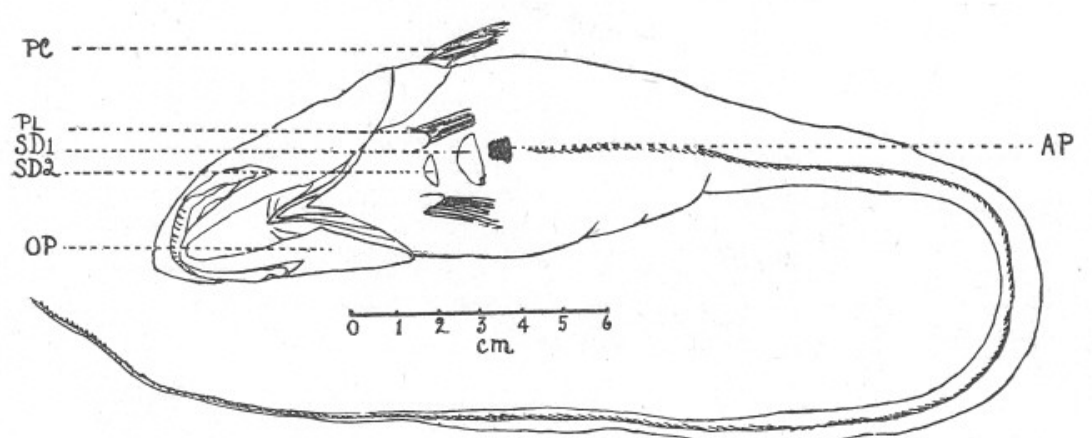

FIG. 1.-Ventral view of M. laevis, showing the position of the scale-less depressions SD 1 and 2.

by pressure, or whether it is natural to the fish, is impossible to say. It seems constant in all the specimens examined.

If the base of the anal papilla be examined with a seeker, a circular cleft will be found encircling the papilla, which is the opening of the duct of the luminous organ. The skin in this region is remarkably thickened and heavily loaded with black pigment. At the scale-less depressions the skin seems much thinner, especially at the anterior depression, where it is quite translucent except for small round melanophores scattered over it.

Dissection of the body wall at this point reveals the luminous organ, which is seen to lie among the muscles anterior to the rectum, and immediately behind the anterior and above the posterior scale-less depression. The relation of the gland to these other structures is indicated by Text Fig. 2, which is a very diagrammatic sagittal section through the middle of the gland and rectum.

The rectum is represented at $R$ with very thick black walls and much- 
pleated epithelium. It is seen protruding below as the papilla. The luminous gland is LG, and its duct is shown at D, passing downwards. The figure seeks to indicate that at this point the duct encircles the rectum - a point which will be again referred to. The scale-less depressions are indicated by SD 1 and SD 2, the latter being headward. L 1 and $\mathrm{L} 2$ are two remarkable hyaline lens-like bodies, the one lying beneath the gland, the other anterior to it. Their relation to the gland and to the scale-less depressions is suggestive, and will be discussed below.

ML points to portions of the heavy sheaths of black pigment which partially or wholly enwrap all these organs.

Seen from above, the organ appears as a fluted swelling arising at the

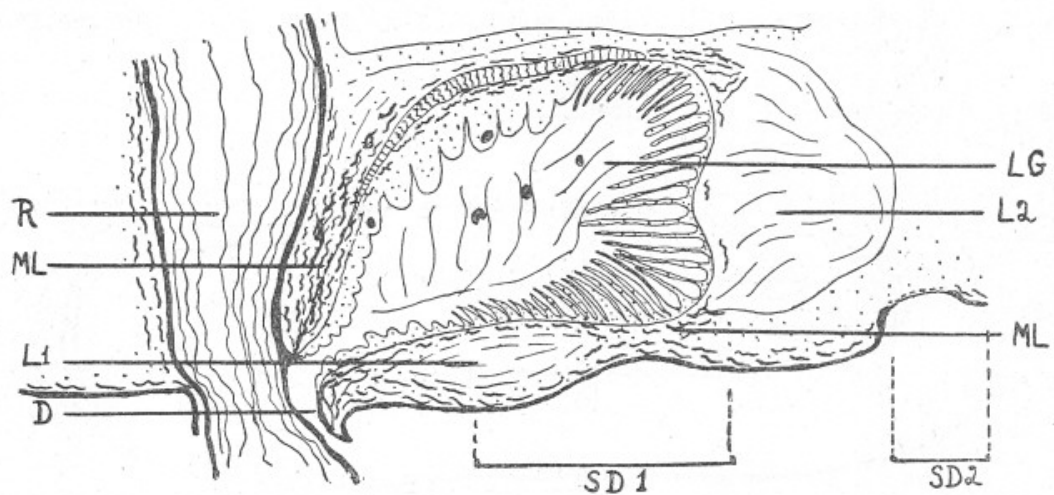

FIG. 2.-Diagrammatic sagittal section through luminous organ of $M$. laevis, showing the relation of the structures. SD 1 and 2, positions of depressions.

point where the rectum passes down from the coelome to the body-wall. So closely does the organ embrace the rectum that the latter appears to pass through the hinder part of it. The swelling is covered by the silvery peritoneum, but at the periphery abundant melanophores are present, with branched and ramifying processes.

The gland is usually between 2 and 4 millimetres in length, but in large specimens it may be 7 or more millimetres.

\section{The Duct.}

Plate I, Figs. 1-3, represent three sections from a series cut transversely to the rectum. The rectal papilla is bent forwards, hence Fig. 1, which is a section very near the anus, includes a long tongue of tissue, which is the papilla cut obliquely. It consists chiefly of connective tissue, containing black pigment, and rich in blood sinuses (BV). The lumen of the rectum, very near the anus, is at $R$, and in this section is not 
complete; a little faecal matter is present. Even at this point the luminous duct is seen at LD, with its characteristic epithelium.

Fig. 2 is at a slightly higher level, near the base of the papilla. The rectum is complete, represented as a much-pleated tube, with the lumen well defined and patent. The epithelium lining the rectum is seen to be very different from that lining the luminous duct. The difference is indicated in Text Figs. 3 and 4, which are both drawn to the same scale. The epithelium of the rectum is regular, columnar, and compact, with the nuclei regularly arranged, and the cytoplasm abutting on the lumen slightly denser than elsewhere. The epithelium of the duct is sharply distinct, being irregular in outline, its cells are indefinite, vacuolated, with their outlines difficult to determine; their nuclei are scattered
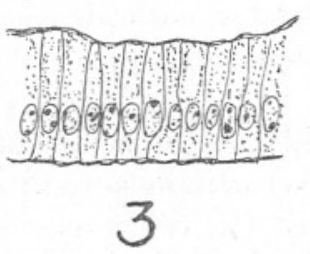

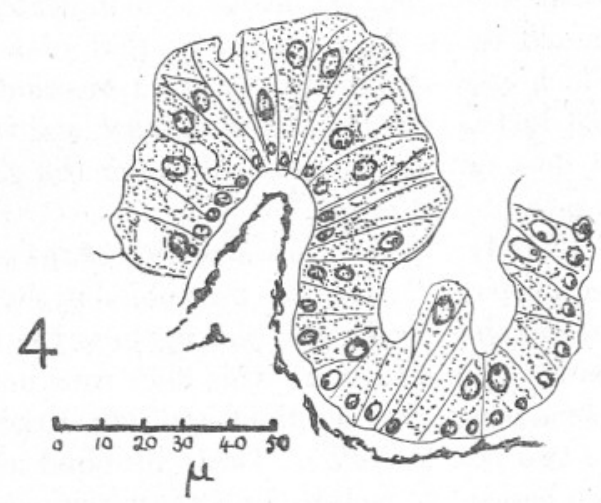

Figs. 3 and 4.-Portions of the epithelium of the rectum and duct respectively, to the same magnification.

at all levels, and the cytoplasm is not more clearly defined at the surface of the epithelium: In Plate I, Fig. 2, the luminous duct is beginning to encircle the rectum. As before, abundant blood sinuses are present, and melanophores (ML) are very abundant in the connective tissue, both scattered, and as definite layers underlying the epithelium of the rectum, of the duct, and in the parts adjacent to the duct.

Fig. 3 is a third section, which shows the remarkable relation which the duct bears to the rectum. The latter is seen as a completely isolated body surrounded by the luminous duct, which entirely encircles the rectum for a short distance. At one side, the duct is seen slightly drawing away from the rectum; this indicates the headward direction, in which the duct will run forward to the gland. Some striped muscle appears in this section; it is doubtless part of the ordinary somatic muscles of this region. This section also shows particularly well the arrangement of the melanin sheaths (ML). A dense sheath surrounds the luminous 
duct, a second lies beneath its epithelium, a third lies beneath the corresponding epithelium on the rectal side, a fourth beneath the epithelium of the rectum itself. Besides these, melanophores are everywhere scattered through the connective tissues.

Plate II, Fig. 4, represents a section at the level where the duct runs forward and upward to the gland. The rectum is no longer completely surrounded by the duct, which has drawn away from it at the hinder end. The duct is seen in oblique horizontal section. It is a flat cavity as broad as the rectum. Plate III shows the duct again in sagittal section. At this level the duct is very indefinite, apparently having a number of tubules and sacculi which communicate with the gland, and no doubt serve to collect the secretion. There is, therefore, no distinct orifice by which the gland communicates with the duct; the relation should rather be regarded as that of a tubular, or sponge-like organ which passes without a sharp transition into the duct. In any case, the duct is very broad and shallow, and taps the gland over a wide base. It does not extend forward under the gland for more than $\frac{1}{4}$ to $\frac{1}{3}$ the length of that organ.

Plate II, Fig. 5. Here a portion of the actual gland is seen in horizontal section $(G)$. The rectum lies behind it, separated by a partition laden with melanophores. Behind this again is the kidney duct $(\mathrm{K})$, which is well shown in this section; this duct runs down parallel to the rectum and opens behind it. To right and left of the line joining rectum and gland lie two pouches (PP). These are blind upgrowths from the duct, which run beside the rectum for a short distance and then die out.

In some of the sections the luminous duct is seen to contain fragments of the secretion.

\section{The Gland.}

The luminous gland is oval in shape, flattened anteriorly, and tapering posteriorly. It is firmly bound in connective tissue, and is very definite in shape, being in no way a diffuse gland. It lies headward of the rectum, with its duct leading backwards and downwards to surround this organ. Plate III is a somewhat diagrammatic sagittal section of the gland, slightly to one side of the middle line. The rectum $(\mathrm{R})$ is, therefore, obstructed by long tongues of tissue, which are the pleated walls of the rectum in longitudinal section.

There is an extraordinary amount of pigment about the gland. This is specially dense in the partition between the rectum and the duct and gland, where the connective tissue is loaded with melanophores (ML). This pigment also occurs in the connective tissue wrapping the organ, almost entirely surrounding it. The walls of the rectum are also heavily pigmented. In this drawing a portion of the coelome (C) is seen, and 
below it a portion of the body-wall (CT) with connective tissue and some muscle, which will be referred to later.

Headward of the gland (L 1) is seen a section of one of the lens-like bodies referred to previously, and below the gland is the second (L 2). They are apparently hyaline connective tissue, with indications of a concentric striation. Further work will be done to make sure whether these lens-like bodies are part of an optical apparatus for casting light from the gland itself. At first sight it seems unlikely, as the organ is well surrounded with pigment, and the gland itself does not seem to give any light when cut out, apart from that of the luminous secretion which inevitably smears itself over the organ.

The headward part of the gland seems to be most active in secretion (S), and here the clumps of secretion, deeply stained, can be seen radiating in lines towards the centre of the gland, usually growing larger as one
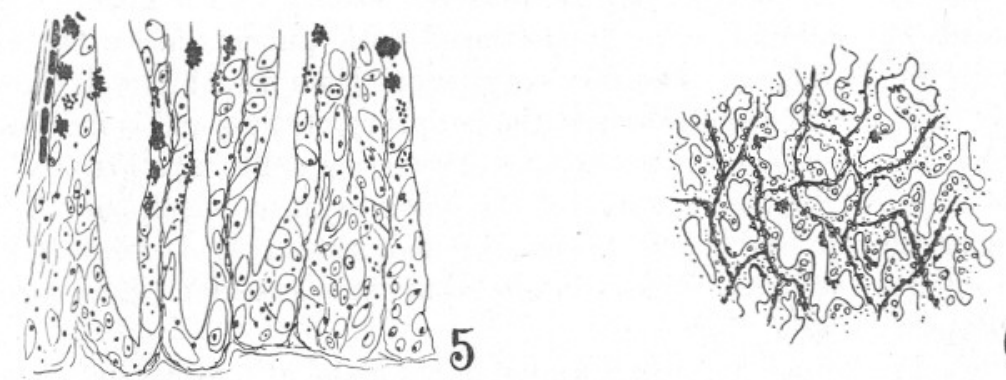

Figs. 5 and 6.-Longitudinal and transverse sections respectively of the secreting portion of gland.

follows them in. "A high-power view of this region is given in Text Fig. 5. This represents the base of some of the long tongues of tissue which are seen to project into the gland. The granules of secretion arise in the cells lining these tongues of tissue, and appear as very deeply staining bodies in the cytoplasm; when set free into the lumina of the gland, they become much larger in size, rather hyaline and less deeply staining, and now measure from 1 to $1.5 \mu$. But more usually they appear as dense balls or aggregations of granules, which cling together to form lumps from $20-30 \mu$ in diameter. These are the black objects shown in the drawings of the gland. Text Fig. 6 is drawn from Plate IV, and shows the appearance, in transverse section, of the secreting tissue of the gland. The granules of secretion are again seen in the walls lining the lumina.

Plates III and IV show the structure of the gland. It is seen to consist largely of long folds of tissue which arise at the periphery and extend towards the centre. Plate III shows the appearance of the folds in longitudinal section, and Text Fig. 5 shows the folds more highly magnified. 
A strand of fibrous connective tissue is seen to run in the centre of the folds, no doubt acting as a support, and fine blood-vessels are also present in the folds, bearing the elongated and deeply staining corpuscles. A row of such corpuscles are shown in Text Fig. 5, to the left.

Towards the hinder end of the gland the structure becomes less definite, the spaces in the connective tissue which largely forms this portion functioning as collecting vessels (CV) or reservoirs, which mainly lead in a downward direction and contain abundant secretion. The folds, as indicated above, take here the form of stout walls, consisting chiefly of connective tissue, the epithelium lining the lumina containing no granules of secretion. They contrast with the folds at the anterior end of the gland, which are long, very slender, and consist largely of a vigorously secreting epithelium, with a small strand of connective tissue only. There is little doubt but that these structures are of essentially the same nature.

Plate II, Fig. 6, represents a transverse section of the gland rather towards the anterior end. It is stained with thionin, hence the cell details do not appear. The very complete melanin sheath is well shown (ML), the secreting epithelium at the periphery of the gland is indicated (S) by the very deeply stained masses of secretion radiating centripetally. The folds (F) appear in virtue of the black pigment which they bear, they are seen to lead chiefly downwards, and contain blood-vessels (BV); the lumina between them contain abundant secretion. The arrow indicates the middle line.

Plate IV shows a horizontal section of the gland at a rather high level. The rectum is seen in transverse section as a pleated tube $(R)$, and between it and the gland is again seen the heavily pigmented partition (ML). Blood spaces (BV) are to be seen in section, while two masses of muscle (M) appear on either side of the rectum. These are typicál striped muscles and seem to have no connection with the present organ. The secretory part of the gland is herè seen $(\mathrm{S})$ in transverse section, the folds of tissue are seen to be united at their bases to give a honeycombed or cerebrated appearance. Text Fig. 6 is an enlargment of a portion of this region; a strand of connective tissue, bearing a certain amount of pigment, is seen to run in the folds; this strand is also shown in longitudinal section in Text Fig. 5. At the anterior end of the gland is seen a strut of strong fibrous connective tissue $(G)$ which projects into the gland. This is undoubtedly a skeletal structure, and at the top and at the sides of the gland there are other such struts which unite to form a meshwork. They are probably instrumental in enabling the gland to keep its shape or to return to it after compression.

In Plate III a muscle layer is seen lying immediately above the gland, running thence backward and downward in the partition between gland and rectum. It is an unstriped muscle, and apparently forms a sheath 
at least around the hinder part of the gland, and possibly of the duct also. It is quite distinct from portions of the ordinary striped muscle of the body-wall, and is also visible in other views of the gland, though less well shown. It is seen in horizontal sections, such as Plate IV, as a layer lying between the gland and the melanin sheath, and occupies a similar position in Plate II, Fig. 6, where it is seen to form a sheath about the gland. It is probably closely connected with the function of compressing the gland to cause emission of the secretion, and probably originates from the splanchnic muscle of the rectum.

The nerve supply of the gland has offered great difficulty. There seems to be no conspicuous nervous organisation, and further work must be done with material specially prepared for neurological work.

Summing up, there is present in this fish a gland, lying in the body wall in front of the rectum, between and behind the pelvic fins; this gland is supported by connective tissue struts internally, a muscle layer, sheaths of connective binding tissue and of pigment, and a duct which opens backward and downward to the exterior as a tube completely surrounding the rectum. Though it is possible that there is an optical apparatus for casting light from the organ, it seems improbable, chiefly on account of the already well-marked secretory function of the gland, and also on account of the abundant pigment which seems to form a light proof sheath about all structures in connection with the gland.

As to the homology of the organ, it is probably to be regarded as a glandular area about the anus, which has become invaginated to form a pouch, and secondarily folded to give an enormous internal area of secretion, while becoming specialised for the secretion of luminous material.

Von Lendenfield (1887) in his notes on the luminous fish collected by the Challenger, suggests (p. 288 and p. 384) that the original forms of phosphorescent organs in fishes arose from the small slime-glands of the skin, which by chance may have produced a slightly phosphorescent slime, as have those of some Batrachians. This would perhaps be of advantage to a fish living in great depths, and progressive evolution could have resulted in the production of a slime more and more luminous.

\section{NOTES ON THE SECRETION.}

When the fish are shot from the trawl at night, $M$. laevis is at once noticeable by the sécretion, which smears the belly of the fish, and may spread over other fish. The secretion is mucous and viscid, adheres to the hand or to an oilskin, and glows quite perceptibly in lamplight. The glow of the pure secretion is distinctly blue, but the solution in sea-water glows bright green. In bright daylight, the secretion appears greenish 
yellow, and when obtained by squeezing the abdomen of the fish, is usually mixed with fæces.

In some cases there is, no doubt, a spontaneous emission of the secretion by the dying fish, but it is difficult to say with certainty whether this is always the case, as the weight of overlying fish might cause the squeezing forth of the secretion. It suggests a comparison with Pholas dactylus, which Dubois (1892) shows to be permanently luminous when moribund.

Harvey (1922), in his work on Photoblepharon and Anomalops, shows that in these fish the luminous organs, while presenting the appearance of secreting glands, do not pass out any luminous material to the exterior. The pores which are present, and were noticed earlier by Steche and other workers, are to be regarded as exits for dead bacteria, the light of these fish shown by Harvey to be due to symbiotic bacteria multiplying within the organs.

It is quite certain that $M$. laevis actually pours forth a secretion, and I am satisfied that the light is not due to bacteria. Not only do the sections of the gland show no sign of bacteria, but smears of the fresh slime, made on board by Dobell's method (1911), show no sign of bacteria when stained with methylene blue. Instead, the granules of the secretion are seen in great numbers, very deeply stained, together with occasional cell fragments.

Moreover, the experiments made with the secretion, shortly to be described, indicate beyond much doubt that bacteria are not responsible for the luminescence in this case.

Each fish, when the abdomen is squeezed, yields a large viscid drop of greenish-yellow slime. The actual quantity obtained naturally varies slightly with the size of the fish, and the state of the organ, but in any case it seems to be enormously greater than that obtainable from other luminous organisms, and $M$. laevis seems to be a form exceptionally favourable for work on animal light.

It has been possible to carry out only a few crude experiments under the difficult conditions experienced at sea on a steam-trawler, but these are given below, and may be of use in future work on this type of luminescence.

\section{(a) The Solution in Sea-Water.}

When the slime in a dark room is allowed to pour down the side of a glass tube into sea-water, it forms drops which rapidly dissolve, giving a very bright, greenish-blue phosphorescence. The secretion squeezed from ten fish was dissolved in about 25 c.c. of sea-water. This solution did not long remain uniformly luminous, but the light became confined to a layer in contact with the air, at the surface of the solution. The optimum brightness 
could only be maintained by constant shaking. The solution, viewed in the dark, has a turbid or granular appearance, the granules appearing to whirl about on agitating the fluid. "It is as if granules were dissolving with light emission" (Harvey, 1924). A strong solution, moreover, shows stratification, as if the granules tended to aggregate.

In total darkness the solution, described above, was photographed. This photograph is reproduced in Text Fig. 7. It was taken with an ordinary Ensign folding camera, using "Kodak " N-C films, at a distance of 5 feet with thirty seconds' exposure. The photo shows the solution lying at the bottom of the honey-jar which contained it, the lower and less distinct shape being the reflection of the light on the polished wood of the table.

A crude photometric experiment was performed with the same solution. A grease-spot photometer was set up, and the honey-jar containing

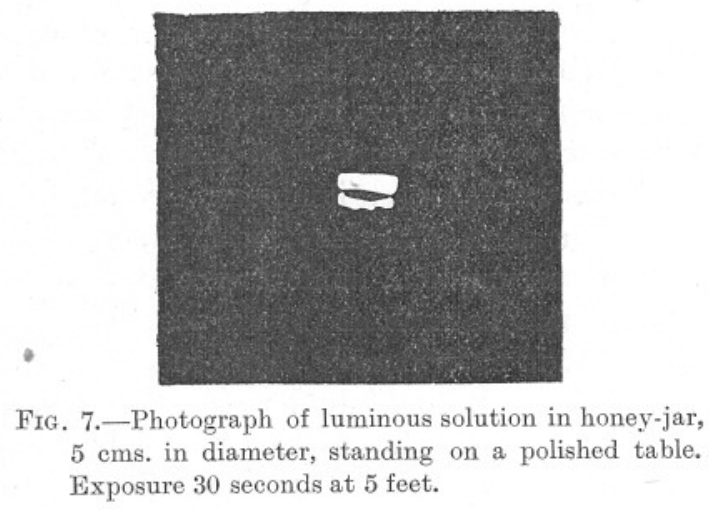

the secretion was placed at a distance of $8 \mathrm{cms}$. from the ${ }^{\top}$ screen, ${ }^{F}$ measured from the centre of the honey-jar, which was $5 \mathrm{cms}$. in external diameter. Now an ordinary paraffin candle was lit, and advanced towards the opposite side of the screen until the bright green glow of the solution was no longer to be seen on the grease-spot, which now appeared bluish black. It was possible to find this point with some sharpness if the luminous solution was kept well agitated. The distances of candle and solution from the screen were now measured. They were as $8 \mathrm{cms} .: 22 \mathrm{cms}$. This gives a candle-power of approximately $\cdot 14$.

The intensity of the glow also naturally depends on the quantity of solution used. Just sufficient of the same solution to cover the bottom of the honey-jar was used for a similar photometric experiment. The distances were now as $4 \mathrm{cms}$. : $24 \mathrm{cms}$. ; a candle-power of approximately $\cdot 029$.

Further experiments were made with the solution. It was found 
possible to read the title of a daily paper at $70 \mathrm{cms}$. , and the hands of a clock at $150 \mathrm{cms}$., both eye and solution being at this distance. The small print of a newspaper could be read easily when the solution was held against the paper, and it could also be used as a "torch " to find knives, matches, pencils, etc., on the floor. Held in the middle of the cabin, one could distinguish objects on the walls, such as clothing, papers, and fittings.

It is a strange thing that so much oxygen is apparently necessary for the steady glow of a strong solution that it must be kept in constant agitation. It suggests that the extraordinary brilliance of the glow is only obtained by a rate of oxidation far in excess of that found to obtain for such luminous forms as Cypridina (Harvey), which are luminous at extreme tenuity of oxygen. One of the facts that guided Harvey to the conclusion that the light of Photoblepharon and Anomalops is due to bacteria was their high oxygen consumption, as shown by the fact that the light only appeared where the material was in contact with the air, and that an emulsion of the glands of these fish becomes, as in the present subject, luminous only in the layers in contact with the air. He shows (loc. cit.) that the oxygen consumption of luminous bacteria is far in excess of that of forms which are self-luminous. As stated earlier, experiments and observations point to the fact that in $M$. laevis, in spite of this high rate of oxygen consumption, luminescence is not due to bacteria, and the phenomenon may be explained by the possibility of the luminous material being present in exceptionally high concentration.

As the sea-water becomes more dilute the colour changes, first to green, and then to a pale green or white colour. The light is still visible at extreme dilution-three drops of pure secretion were dissolved in seawater and then poured into a gallon of sea-water in a canvas bucket, the bucket now appeared as though filled with milk, very distinctly luminous and pale white. Twenty-four hours later the bucket still appeared luminous, the solution having soaked into the walls.

The solution in sea-water remains luminous for a very long time. A jar was found to be still feebly phosphorescent after six days, but usually a strong solution begins to putrefy after forty-eight hours, and later becomes quite turbid with growths. This putrid solution may become perceptibly brighter on shaking up this turbid sediment, a fact which compares in an interesting way with Harvey's statement, in Animal Light, that bacteria can revive the light of a dead luminous solution by reducing the oxidisable substance, and thus again rendering it available for light production.

The more dilute solutions of the secretion are uniformly luminous throughout. 


\section{(b) The Solution in Distilled Water.}

When allowed to trickle down into distilled water, the secretion forms very brightly luminous beads, which dissolve on shaking and fade out immediately. The glow cannot be revived by addition of sea-water, nor by treatment with a Luciferin solution (see below). But if the secretion be first dissolved in a small quantity of sea-water, and then diluted with distilled water to almost any extent, there is neither extinguishing nor brightening of the light, the new solution having the same appearance as a corresponding solution in sea-water. The glow soon fades out, however ; the exact time is not certain, but it is usually between eight and twelve hours.

\section{(c) Other Observations.}

The secretion was allowed to stand over crystals of sugar for nine hours. The glow was not extinguished immediately, and after this interval the glow reappeared as before on dissolving in sea-water.

When poured on to crystals of $\mathrm{MgSO}_{4}$, the glow of the solution was instantly put out, but was again revived on dissolving in a large bulk of sea-water after standing over these crystals for nine hours. These two experiments are especially suggestive in showing that bacteria can hardly be responsible for the light.

The temperature at which the glow was extinguished could not be determined, but it is worth noting that it was slowly extinguished by placing a tube of secretion in a mug of cocoa just cool enough to sip. It was also soon put out by being suspended over the cylinders in the engine-room, but here the ascending currents of air may be very hot.

\section{LUCIFERIN AND LUCIFERASE.}

Harvey suggests that all animal luminescence is due to the same fundamental principle, namely, the burning of luciferin to oxyluciferin in presence of the ferment luciferase. Attempts were made to demonstrate these bodies in the present fish, and I am satisfied that it is possible to show that here also the luminescence is of the above type.

Dubois (1887), in his work on Pholas, notes that the luminous tissue of this mollusc was extinguished by exposure to hot water, but that light was again renewed when over the darkened tissue was poured a solution containing the luminous secretion of Pholas which had exhausted its light. He suggested the names luciferin and luciferase, the last being a ferment which is destroyed by heat, but is still present in a solution of a luminous secretion which has burnt up all the available luminous material, luciferin.

A solution of luciferase was prepared from $M$. laevis, as mentioned 
in a preceding paragraph, by allowing a solution of the secretion, much diluted with distilled water, to die out, a process which takes place between eight and twelve hours after solution. Oxidation seems more rapid when distilled water is added, as the sea-water solution remains luminous for days.

A luciferin solution was obtained by placing a strong solution of the secretion of the fish in a hot fluid, until the solution was completely dark.

When these two perfectly dark solutions are mixed, a distinct glow results, which lasts for some time.

As a control experiment, a similar tube of extinguished secretion was placed in an equal bulk of distilled water-there was no result.

To this dilute solution of luciferin was added a spot of pure secretion on the top of a pencil. The dark liquid at once "took fire" and glowed distinctly.

Finally, a similar spot of secretion added to distilled water behaved just as a previous experiment indicated. It formed a few bright spangles of light which soon faded out.

Hence the evidence points, in my opinion, to the luminescence of this fish being essentially of the same nature as that of Cypridina, Odontosyllis, Pholas, and fireflies, and it is not to be regarded as due to symbiotic bacteria.

Malacocephalus laevis, however, differs from all other such organisms in the remarkable size of the gland, and the quantity of luminous matter available for examination; in the unusually high ogygen consumption of a strong solution, in the length of duration of the luminescence, and in the fact that the luciferin-luciferase reaction cannot be demonstrated in distilled water, unless the secretion has been previously treated with sea-water.

\section{CONCLUSION.}

The function of the gland seems much more obvious than is the case with many other types of luminous organs. It has no sexual significance, since it is equally well developed in the smallest specimens seen. But it lies between the strong muscles of the body-wall behind the pelvic fins, and may have a special muscular sheath apart from these. Contraction of these muscles would cause the secretion to be shot out, and its use would seem to be exactly analogous to the ink-sac of Cephalopods, but whereas the latter emit a cloud of ink, this fish emits a cloud of light.

I have never seen a fully alive specimen of $M$. laevis, though I have often searched. When thrown back into the water my specimens float motionless, belly upward. But Capt. Jones tells me that off Cape Villano he threw a large specimen overboard alive, and that it emitted a cloud 
of fire, which spread "like a dinner-plate," and apparently remained visible for some time. This leaves little doubt but that the function of the gland is as has been indicated in the previous paragraph.

There is no evidence of the gland being used as a flashing apparatus, in spite of the very suggestive relations of the hyaline bodies and the scale-less depressions with the gland.

We may imagine that a Macrurid possessing this organ would, on alarm, emit a puff of light and then make off in a different direction. Knowing the attractive power of light for many animals, especially fishes, we can understand that a pursuer might pause to investigate the nebula, and enable the prey to make good its escape. Dubois (1892) suggests that Pholas dactylus in a similar way envelops itself in a cloud of light, though here, apparently, the author considers that the effect would be to alarm a persecutor.

It is just possible that the secretion may be used in the same way for attracting the food of this fish. M. laevis feeds on crustacea mainly, such as Cirolana borealis, the crabs Geryon and Gonoplax, Nephrops, Pasiphaë, Crangonids, Pandalus and Amphipods, with other more occasional forms.

Three Macrurids are fairly common along the edge of the continental shelf within the reach of commercial trawlers, namely, $M$. laevis, Coelorhynchus coelorhynchus, and Trachyrhynchus trachyrhynchus. Farran (1924) states that $M$. laevis and C. coelorhynchus are common on the hake grounds S.W. of Ireland, but I have only seen five specimens of $C$. coelorhynchus, and these were taken in $300 \mathrm{f}$., in the greatest depth worked. T. trachyrhynchus is occasionally quite plentiful, and is one of the signs that the ship is fishing near coral.

Now $M$. laevis has small and thin scales, feebly armed with small spines, but it has a very well-developed luminous organ. C. coelorhynchus has well-armed spinous scales, and possesses, between the pelvic fins, a naked, pigmented patch recalling that of $M$. laevis; and dissection again reveals a flat pigmented sac lying in the body-wall adjacent to this pigmented patch. Material has been prepared for a further examination of this organ, but at present it gives one the appearance of being a rudimentary organ, yielding no secretion, but connected with the anus by a pigmented, functionless duct.

T. trachyrhynchus has very strongly armed scales, forming a thick and heavy coat of mail, and as far as present work has shown, there is no trace of a luminous organ. The scales of these three fish are photographed in Farran's paper (1924), but that of T. trachyrhynchus is probably from a young specimen, as my specimens have a very thick scale with three strong teeth, while Farran's scale shows but one strong central spine, and two small ones. He states, however, on p. 122, that in a 
larger specimen the scale bears "one large, and usually, two smaller spines, short and robust, the whole scale being thickened and massive."

Pending further work on these fish, I would suggest that the increasing efficiency of external armour has rendered unnecessary the protective device of a luminous organ, and that these three forms show how the gland might have been reduced as the scale armour increases in importance. The scale of $M$. laevis is much nearer the gadoid type than any of the others, and Macrurids are regarded as derived from the Gadidæ.

As these three forms are not closely allied, according to the arrangement of Gilbert and Hubbs (1916), it suggests that the organ may be widely distributed among Macruridæ, and further work on other species might reveal its presence.

M. laevis occurs in the stomach contents of hake, but in a fresh condition, and it is probably to be placed among the adventitious contents which have been snatched up during the hake's struggles in the trawl. I have not so far seen a specimen which showed definite signs of digestion; hence, having in mind the extraordinary voracity and the catholic appetite of the hake, one must suppose that the protective device of a luminous gland fulfils its purpose efficiently.

I wish to acknowledge my thanks to Professor Newton Harvey for his help and correspondence, to Dr. E. J. Allen, F.R.s., Dr. Orton, Mr. Ford, and Mr. Russell for help and suggestions.

\section{SUMMARY.}

A luminous organ of a hitherto undescribed type has been found in a Macrurid fish. This organ is described in the present paper. It consists essentially of an epithelium for the secretion of luminous substance, which has been thrown into long folds and wholly invaginated to form a gland. This gland is bound in connective tissue and has a compact appearance, and is furnished with supporting tissue internally. The duct is a flat and wide passage, continuous with the gland, which opens to the exterior about the anus in such a way as to surround the lower part of the rectum. The gland lies in the thickness of the body-wall forward of the rectum and between and behind the pelvic fins.

The nature of the secretion is discussed and some experiments described. The luminescence appears to be due not to bacteria living as guests within the tissues of the fish, as has been shown for other species, but is essentially due to the well-known reaction wherein a substance luciferin is burnt to oxyluciferin in presence of the ferment luciferase, with emission of cold light. 


\section{LITERATURE.}

1887. Von Ledenteld, R. "Challenger" Reports. Zoology, Vol. XXII, Appendix B.

1887. Dubois, R. De la fonction photogénique chez le Pholas dactylus. C.R. Acad. Sc., Vol. CV, p. 690.

1892. Dubois, R. Anatomie et Physiologie Comparées de la Pholade Dactyle. Ann. d. Univ. Lyon, Vol. II, pp. 1-155.

1911. Dobell, C. C. Contributions to the Cytology of the Bacteria. Q.J.M.S., Vol. LVI, N.S., No. 223.

1916. Gilbert, C. H., And Hubbs, C. L. Report on the Japanese Macrourid Fishes Collected by the U.S. Fisheries steamer Albatross in 1906. Proc. U.S. Nat. Mus., 51.

1919. Harvey, E. Newton. The Nature of Animal Light. Lippincott, Philadelphia.

1922. Harvey, E. Newton. The production of light by the fishes Photoblepharon and Anomalops. Pub. No. 312, Carneg. Inst., Wash., 1922 c., pp. 43-60.

1924. Harvey, E. Newton. Recent Advances in Bioluminescence. Physiological Reviews, Vol. IV, No. 4. Oct., 1924.

1924. Farran, G. P. Seventh Report on the Fishes of the Irish Atlantic Slope. The Macrurid Fishes. Proc. Roy. Irish Acad., Vol. XXXVI, Sec. B, No. 8, pp. 91-148. 
PLATE I.

Figs. 1-3.

1. A section through the papilla near the anus. The wall of the papilla cut obliquely, Luminous duct and rectum shown incomplete. Numerous blood sinuses.

2. A section transverse to the rectum at a higher level in the papilla.

3. A section transverse to the rectum at the level of the body-wall. The luminous duct completely surrounds the rectum.

樶 B.V. : Blood sinus. L.D. : Luminous duct. M.L. : Melanophore sheath. M. : Musele. R. : Rectum. Stained with iron-hæmotoxylin. 
PLATE I.
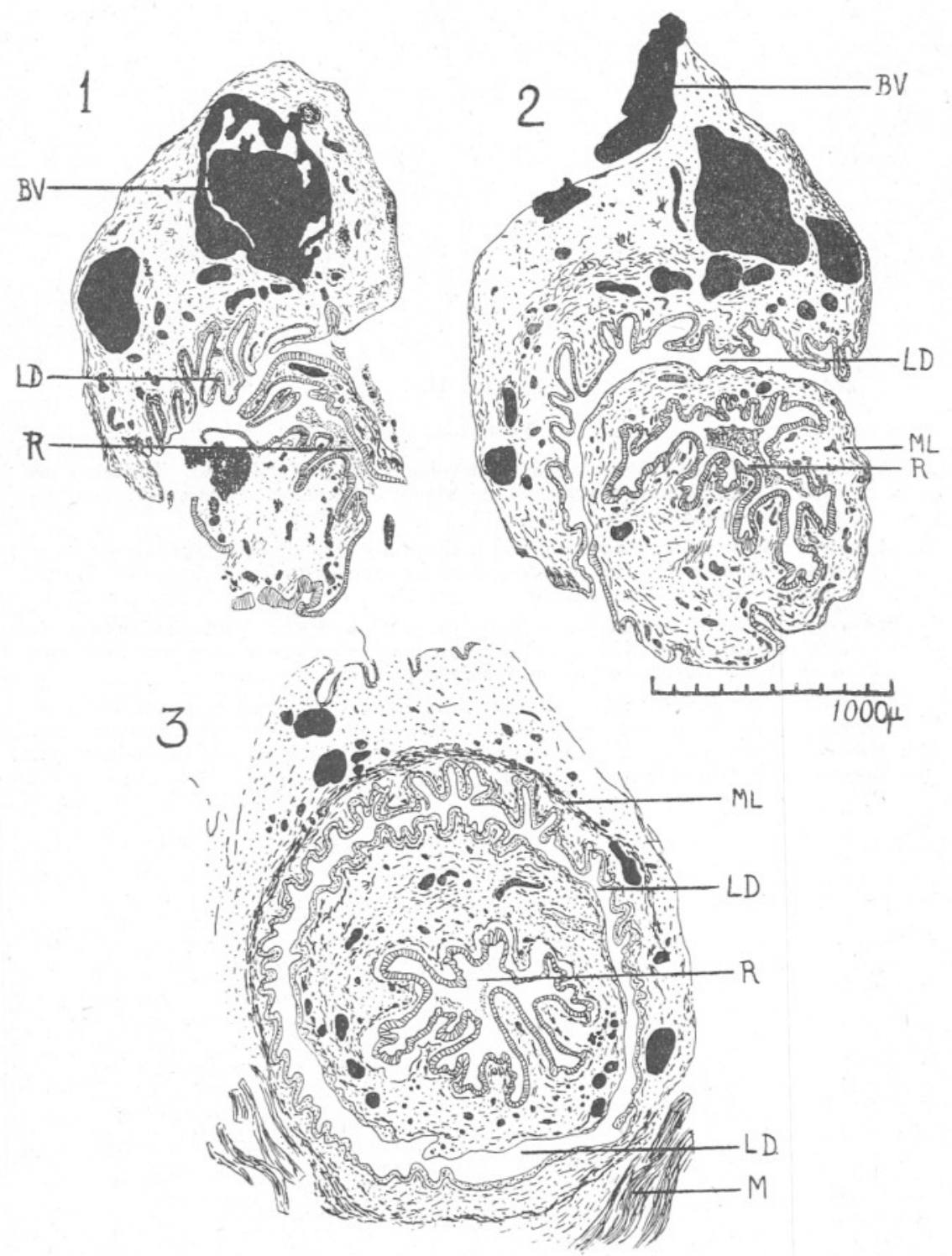

Del. C. F. H. 


\section{PLATE II.}

Figs. 4-6.

4. A section transverse to the rectum at the level of the base of the gland. The luminous duct is seen running forward to the gland, cut somewhat obliquely. Stained with iron-hæmotoxylin.

5. A section transverse to the rectum and horizontally through the gland, a portion of which is shown. The two pouches of the duct are seen. The kidney duct shown. Stained with iron-hæmotoxylin.

6. A low-power view of a transverse section of the luminous gland. Stained with thionin. The radiating lines of lumps of secretion are seen; the melanophore sheath and downwardly directed collecting spaces well shown.

B.V.: Blood vessel. C.V.: Collecting space in gland. D. : Duct of luminous organ. F. : Folds of tissue of gland cut longitudinally. G. : Luminous gland. K. : Kidney duct. M. : Muscle of body-wall. M.L. : Melanophore layers. P.: Pouch of luminous duct. R. : Rectum. S.: Secreting part of gland. 

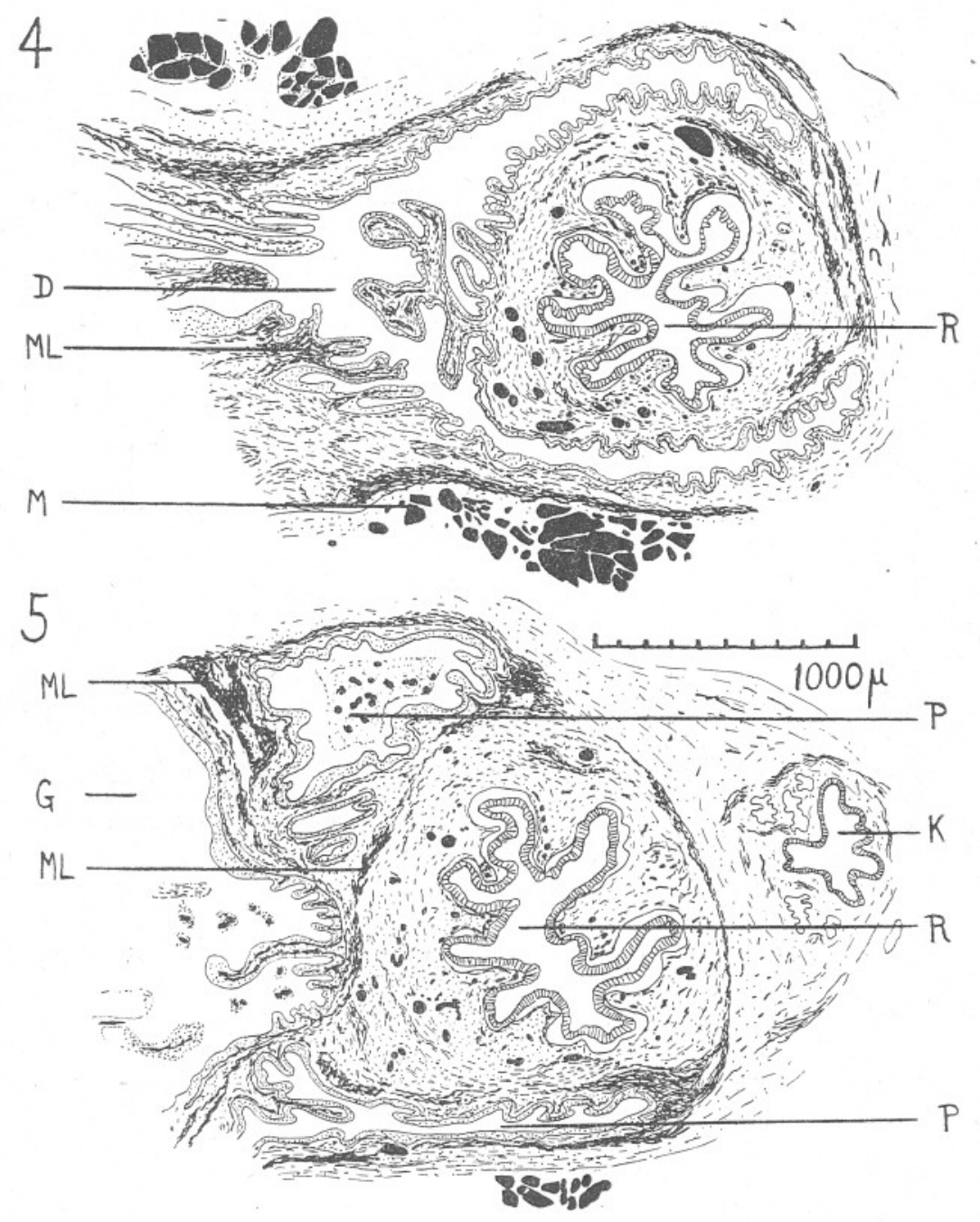

6

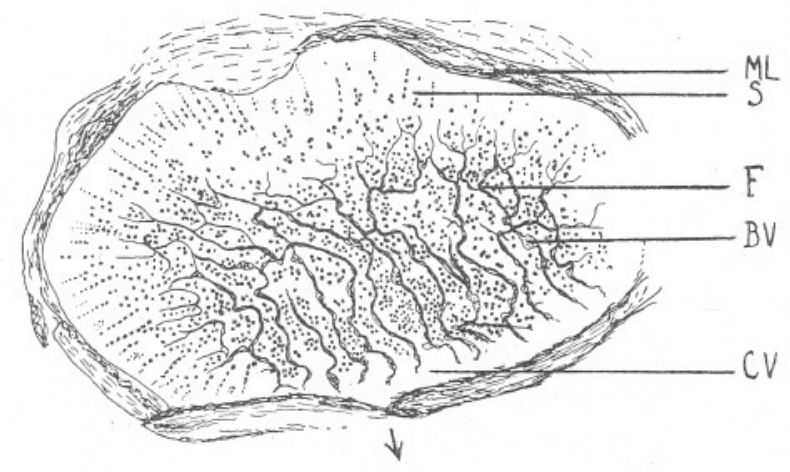

DeL. C. F. H. 
A somewhat diagrammatic sagittal longitudinal section of the gland and duct, slightly to one side of the middle line.

B.V.: Blood vessel. C.: Coelome. C.T.: Connective tissue. C.V.: Collecting space in gland. D.: Duct of luminous organ. Ll and L2.: Lens-like bodies associated with organ. M.: Muscle layer cut transversely. M.L.: Melanophore layers. R. : Rectum. S. : Secreting part of gland. Stained with iron-hæmotoxylin. 


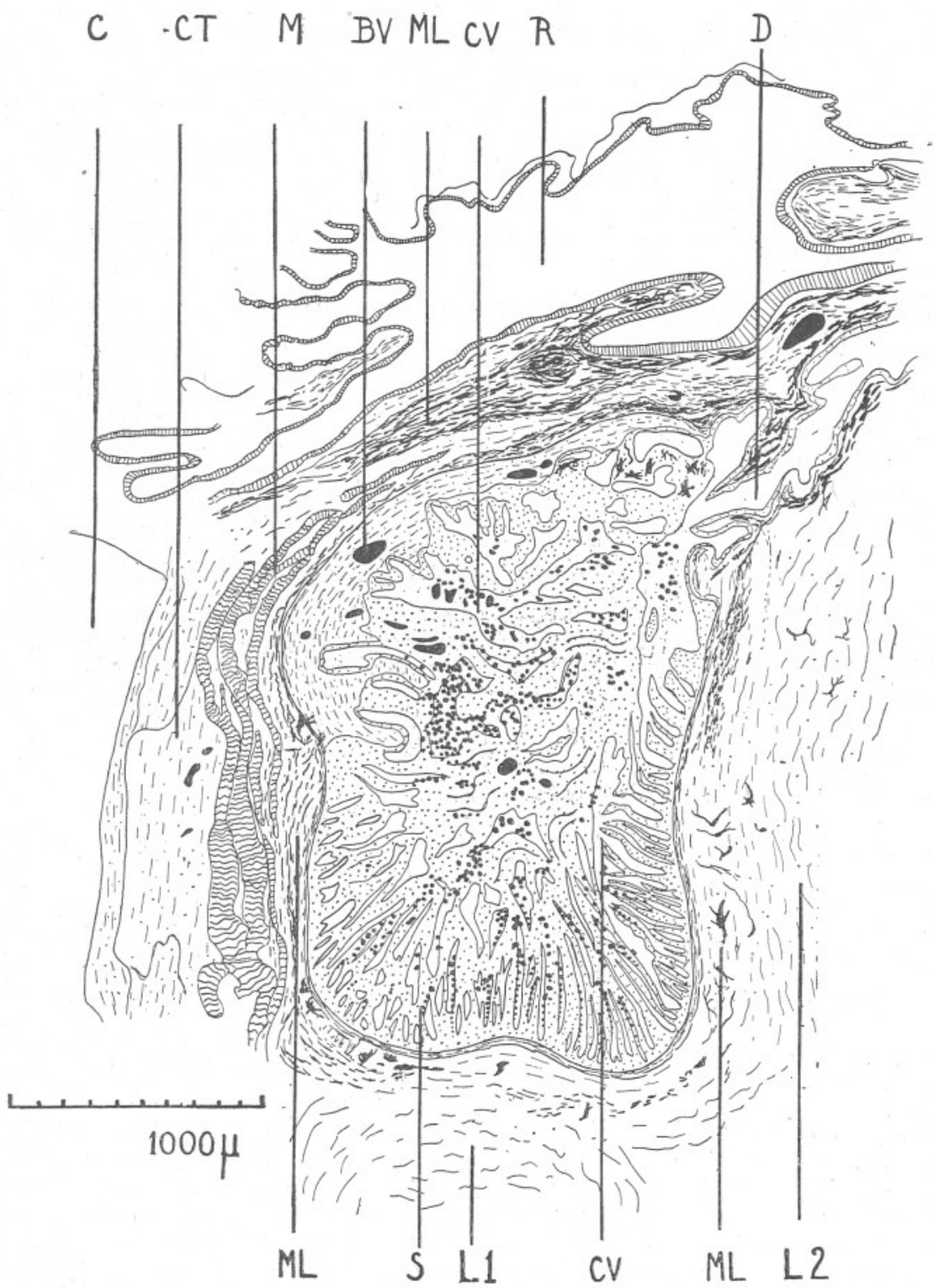

DeL. C. F. H. 
C. F. HICKLING.

\section{PLATE IV.}

A horizontal section through the gland, cutting the rectum transversely

B.V.: Blood vessels. C.T.: Connective tissue. G.: Strut of connective tissue forming a skeletal support. M.: Muscle of body-wall. M.L.: Melanophores. R.: Rectum. S. : Secreting part of gland. Stained with iron-hæmotoxylin. 


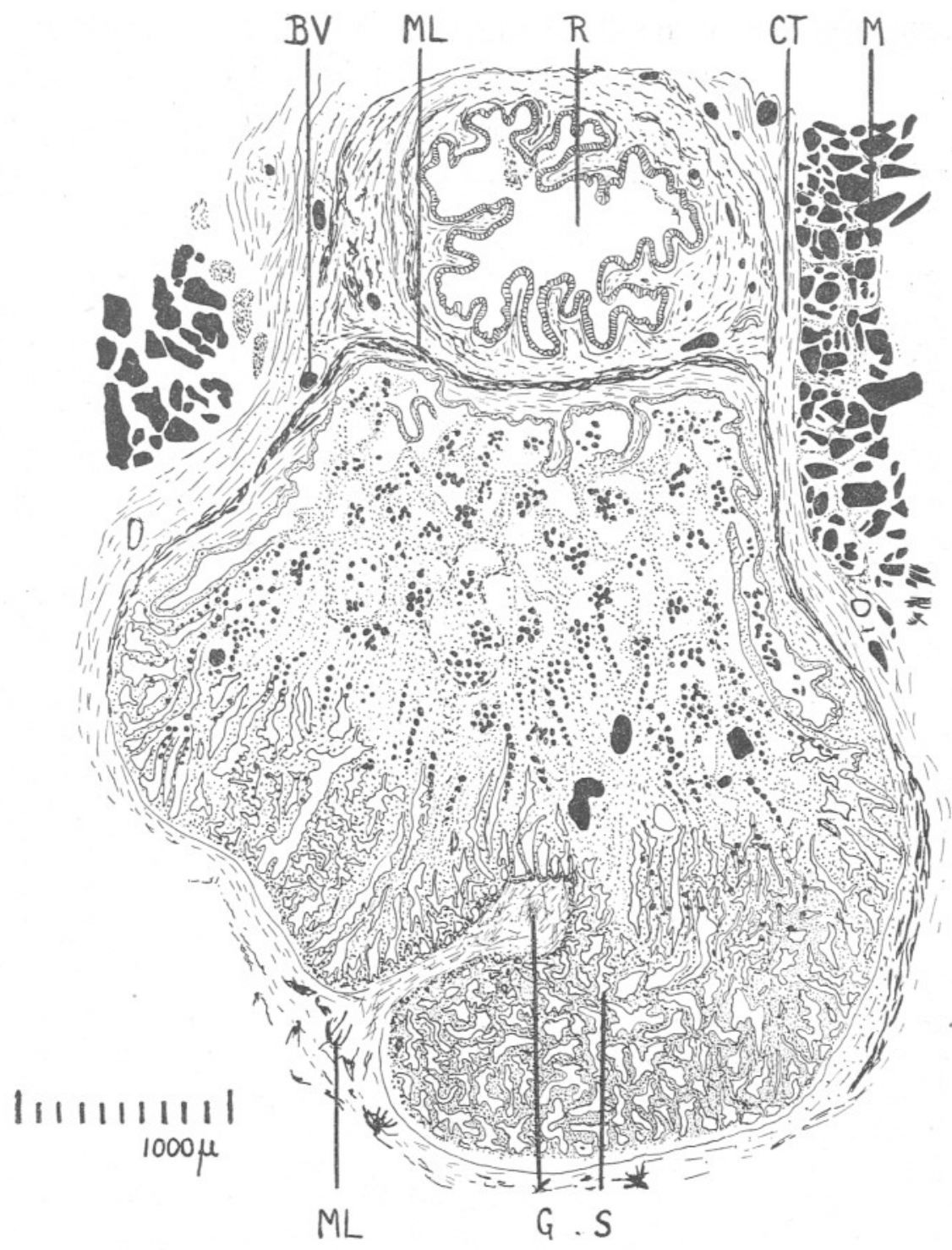

DEL. C. F. H. 